\title{
ASPECTOS DO DESENVOLVIMENTO OVOCITÁRIO NO PEIXE-PULMONADO SUL-AMERICANO, LEPIDOSIREN PARADOXA FITZINGER (DIPNOI) ${ }^{1}$
}

\author{
Paulo de Tarso da Cunha Chaves ${ }^{2}$
}

\begin{abstract}
SOME ASPECTS OF THE OOGENESIS IN THE SOUTH AMERICAN LUNGFISH, LEPIDOSIREN PARADOXA FITZINGER (DIPNOI). Histological changes in the oocyte development of South American lungfish are described. During maturation, pre-vitellogenic and vitellogenic phases could be distinguished, and they are similar to those of teleost fishes.

KEY WORDS. Reproduction, amazonian, Lepidosiren paradoxa, Dipnoi, Osteichthyes
\end{abstract}

Os Dipnoi são hoje propostos como sendo o grupo-irmão dos Tetrapoda (LAUDER \& LIEM, 1983). Tratam-se de peixes ósseos exclusivamente dulceaquícolas, cuja representatividade atual restringe-se a 6 espécies: 4 na África (gênero Protopterus Owen, 1839), uma na Austrália (gênero Neoceratodus Castelnau, 1876), e uma na América do Sul (Lepidosiren paradoxa Fitzinger, 1837 - Lepidosirenidae, Lepidosireniformes) (LAUDER \& LIEM, op. cit.).

Graças a peculiaridades como a presença de coanas e a prática de respiração aérea, os dipnóicos já geraram diversas pesquisas de cunho fisiológico (e.g. JOHANSEN, 1968). Seu hábito de vida em ambientes periodicamente secos também motivou investigações sobre o tegumento (IMAKI \& CHAVIN, 1975; FOX, 1989). No plano reprodutivo, sabe-se que produzem ovos adesivos a plantas, os quais são aerados e guardados pelos machos (BREDER JR. \& ROSEN, 1966).

Este artigo descreve o desenvolvimento dos ovócitos durante a maturação gonadal de Lepidosiren paradoxa, peixe pulmonado conhecido no norte e centro-oeste brasileiro como "pirambóia". Objetiva-se estimar o tipo de desova da espécie, contribuindo assim ao conhecimento de sua reprodução, e comparar o processo de ovocitogênese deste representante de um grupo tão particular de peixes com o que se verifica nos teleósteos, para os quais as descrições são largamente disponíveis na literatura.

1) Contribuição número 744 do Departamento de Zoologia, Universidade Federal do Paraná.

2) Departamento de Zoologia, Universidade Federal do Paraná, Caixa Postal 19020, 81531-970 Curitiba, Paraná. Bolsista do CNPq. 

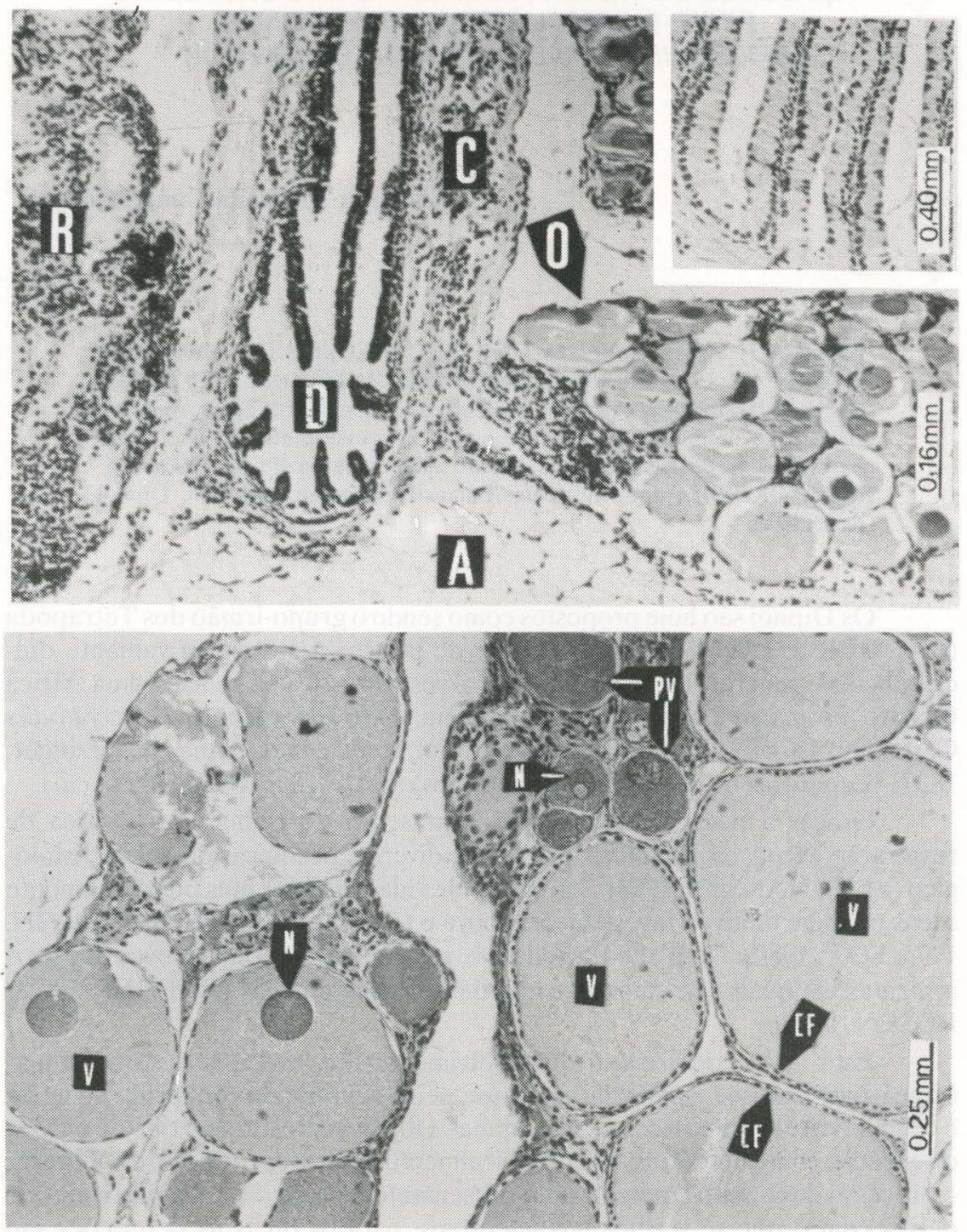

Figs 1-2. (1) Seç̧ão parcial do sistema urogenital de L. paradoxa. (R) rim; (D) ducto; (C) tecido conjuntivo; (A) tecido adiposo; (O) ovário. No detalhe, vista parcial do ducto em outra secção: mostra-se de maior calibre, rico em evaginações, e revestido por epitélio simples prismático. (2) Secção parcial de ovário em maturação. (PV) ovócitos basófilos, pré-vitelogênicos; (V) ovócitos em vitelogênese; (N) núcleo dos ovócitos; (CF) núcleos de células foliculares, envolvendo ovócitos vitelogênicos. Observar a diferença de volume entre as duas fases ovocitárias representadas, e a redução na basofilia citoplasmática ocorrida da primeira para a segunda. 


\section{MATERIAL E MÉTODOS}

Foram analisados histologicamente os ovários de três exemplares fêmeas de L. paradoxa coletados com rede de emalhe, em área de várzea adjacente ao rio Amazonas, próximo a Manaus. As gônadas estavam visivelmente em estágio avançado de maturação, tendo sido extirpadas junto aos tecidos a elas ligados. A fixação do material deu-se em formol 10\%, e o preparo histológico seguiu a técnica de rotina para coloração $\mathrm{HE}$.

\section{RESULTADOS}

Os ovários em L. paradoxa apresentam-se estreitamente associados aos rins, separados destes apenas por tecido conjuntivo, um ducto, e algum tecido adiposo (Fig. 1). A parede do ducto é rica em evaginações para a luz, sendo revestida por tecido epitelial simples prismático (Fig. 1 - detalhe).

A primeira fase ovocitária registrada é ainda pré-vitelogênica, dotada de citoplasma basófilo, sem inclusões, e com núcleo localizado em posição excêntrica (Fig. 2). A seguir tem início a deposição de vitelo, sem uma região específica no ovócito, que provoca um substancial crescimento do volume celular e uma nítida diminuição da afinidade tintorial do citoplasma. Nesta etapa, em torno do ovócito é visível a presença de um primeiro envoltório, a camada de células foliculares, com formato plano (Fig. 2). A maturação prosseguẹ através da deposição de grânulos vitelínicos acidófilos, inicialmente em disposição cortical, mas que gradativamente se expande para ocupar toda a área central da célula (Fig. 3). Finalmente, nos ovócitos maduros, todo o citoplasma está preenchido por esses grânulos. O núcleo mantém-se em posição excêntrica, e a camada de células foliculares permanece plana. Entre esta e o ovócito é agora visível um segundo envoltório, a membrana vitelina, com discreta afinidade tintorial acidófila, e sem estriações distinguíveis sob aumento normal de microscopia óptica (Fig. 4).

Quanto ao desenvolvimento dos ovócitos em conjunto, verificou-se que L. paradoxa enquadra-se no tipo assincrônico: todos os ovócitos descritos podem coexistir num ovário, embora numericamente os pré-vitelogênicos pareçam sempre predominar.

\section{DISCUSSÃO}

A conexão anatômica observada entre os rins e os ovários, aqui ilustrada histologicamente, já foi descrita em HOAR \& RANDALL (1969) como sendo uma das particularidades do sistema urogenital dos dipnóicos. Trata-se de uma diferença em relação à apresentação comum nos teleósteos, em que os ductos genitais têm início na porção terminal das gônadas, sem contato com os rins. Acredita-se que nas fêmeas de L. paradoxa estes ductos funcionem exclusivamente como via genital, ainda que nos machos sejam também utilizados para o transporte de urina (HOAR \& RANDALL, op. cit.). 



Figs 3-4. (1) Folículo ovariano em fase final de maturação. Os grânulos acidófilos de vitelo (GV) ocupam a região central do citoplasma. Núcleo não seccionado. (CF) núcleos de células foliculares. (4) Vista parcial de folículo ovariano maduro. O vitelo acidófilo preenche quase todo o volume ovocitário, e o núcleo (N) mantém-se em localização excêntrica. São visíveis dois envoltórios: a camada de células foliculares (núcleos), mais externa (CF), e a membrana vitelina (MV). 
O tipo de epitélio de revestimento dos ductos (prismático simples) pode indicar a presença de alguma atividade secretora, talvez relacionada à produção de substâncias para a adesividade dos ovos.

Embora L. paradoxa pertença a uma linhagem de peixes distinta daquela dos teleósteos, o desenvolvimento dos folículos ovarianos mostrou-se basicamente o mesmo. Esta conclusão advém da comparação entre os resultados aqui obtidos com aqueles disponíveis na literatura para espécies de Clupeiformes, Characiformes, Siluriformes, Gadiformes e Perciformes (CHAVES, 1988 e 1989a; SUZUKI, 1992). Não foram registradas as células correspondentes às ovogônias dos teleósteos, mas isso provavelmente se deve ao estágio de maturação (relativamente avançado) dos exemplares analisados. Na primeira fase identificada, a basofilia é explicada pelo intenso acúmulo de organelas ribossômicas, preparatório à elaboração de vitelo. O padrão de deposição inicial deste, não em gotículas individuais mas sim homogeneizadas com o citoplasma, é uma diferença do que normalmente ocorre em outros peixes. Nesta etapa, a ausência de afinidade entre o vitelo e os corantes empregados (causa da redução da basofilia citoplasmática) sugere que ele tenha uma natureza lipídica, no que se identifica com o caso comum dos teleósteos. Quanto ao vitelo granular acidófilo, o último a aparecer na maturação ovocitária, é fundamentalmente idêntico em aspecto e local de deposição àquele dos teleósteos conhecidos.

Os dois envoltórios do ovócito, a membrana vitelina e a camada de células foliculares, revelaram possuir a mesma morfologia descrita em diversas espécies de Clupeiformes, Characiformes e Perciformes. O aspecto difere, porém, do verificado por exemplo em Serrasalmus spp. (membrana vitelina de aspecto duplo e com estriações - SUZUKI, 1992), e em Siluriformes e Cichlidae (células foliculares prismáticas, e não planas - GODINHO et al., 1974; BARBIERI et al. 1981; SUZUKI, 1992).

Não foram encontrados indícios de que os ovócitos de L.paradoxa sofram hidratação pré-ovulatória. Este processo, relacionado à flutuabilidade dos ovos que têm hábito pelágico, é característico de teleósteos marinhos (CHAVES, 1989b), fato que explicaria sua ausência nesta espécie.

O tipo de desenvolvimento ovocitário constatado, assincrônico, gera uma expectativa de que $L$. paradoxa seja um desovante parcial, em múltiplos lotes. Tal comportamento é bastante comum em peixes que dedicam cuidados à prole, mas sua estimativa neste trabalho é ressalvada pelo número pequeno de exemplares analisados.

\section{CONCLUSÕES}

O desenvolvimento ovocitário nesta espécie de dipnóico assemelha-se ao conhecido para peixes teleósteos, com diferenças, porém, na apresentação morfológica da vitelogênese.

Quanto à morfologia dos envoltórios membrana vitelina e camada de células foliculares, há maior identidade com espécies de Clupeiformes, de Characiformes e de muitos Perciformes, do que com as de Cichlidae e de muitos 
Siluriformes.

Em L. paradoxa não se registraram indícios de hidratação pré-ovulatória.

\section{REFERÊNCIAS BIBLIOGRÁFICAS}

BARBIERI, M.C.; G. BARBIERI \& M.A. MARINS. 1981. Sobre a anatomia e histologia de ovário de Geophagus brasiliensis (Quoy \& Gaimard, 1824) na Represa do Lobo, estado de São Paulo. Rev. brasil. Biol. 41 (1): 163-168.

BREDER JR., C.M. \& D.E. ROSEN. 1966. Modes of Reproduction in Fishes. Jersey City, TFH Publications, 941p.

CHAVES, P.T.C. 1988. Aspectos convergentes da dinâmica ovariana nos peixes, com uma contribuição à biologia reprodutiva de 14 espécies do litoral de São Paulo. Tese de doutorado, não publicada, Universidade de São Paulo, São Paulo, 123p.

- 1989a. Desenvolvimento dos ovócitos em Harengula clupeola, Urophycis brasiliensis, Eucinostomus argenteus, Isopisthus parvipinnis e Menticirrhus americanus (Teleostei). Bol. Inst. oceanogr., S.Paulo, 37 (2): 81-93.

1989b. Hidratação pré-ovulatória em peixes: um caráter de origem marinha? Rev. bras. Zool. 6 (3): 463-472.

FOX, H. 1989. Tail skin of the dipnoan Neoceratodus larva: fine structure and differentiation. J. Zool. Lond. 217: 213-226.

GODINHO, H.M.; S. FERRI; L.O. MEDEIROS \& J.M.B. BARKER. 1974. Morphological changes in the ovary of Pimelodus maculatus Lacépede, 1803 (Pisces, Siluroidei) related to the reproductive cycle. Rev. brasil. Biol.34 (4): 581-588.

HOAR, W.S. \& D.J. RANDALL (ed.) 1969. Fish Physiology. London, Academic Press, v.3, 1-72p.

IMAKI, H. \& W. CHAVIN. 1975. Ultrastructure of the integumental melanophores of the South American lungfish (Lepidosiren paradoxa) and the African lungfish (Protopterus sp). Cell Tiss. Res. 158: 375-389.

JOHANSEN, K. 1968. Air-breathing fishes. Sci. Am. 219 (4): 102-111.

LAUDER, G.V. \& K.F. LEIM. 1983. The evolution and interrelationships of the actinopterygian fishes. Bull. Mus. Comp. Zool. 150 (3): 95-197.

SUZUKI, H.I. 1992. Variações na morfologia ovariana e no desenvolvimento do folículo de espécies de peixes teleósteos da bacia do rio Paraná, no trecho entre a foz do rio Paranapanema e a do rio Iguaçu. Dissertação de Mestrado,não publicada, Universidade Federal do Paraná, Curitiba, 140p. 